\title{
Comparative Study of HSV Color Model and Ycbcr Color Model to Detect Nucleus of White Cells
}

\author{
Himali Vaghela \\ M.tech(Communication \\ System Engineering) \\ CHARUSAT University, \\ Changa, Anand. 388421
}

\author{
Hardik Modi \\ Faculty of EC \\ department \\ CHARUSAT University, \\ Changa, Anand. 388421
}

\author{
Manoj Pandya \\ Project Manager(PhD) \\ BISAG, \\ Gandhinagar,38207
}

\author{
M. B. Potdar \\ Project Director $(\mathrm{PhD})$ \\ BISAG, \\ Gandhinagar,38207
}

\begin{abstract}
Main objective of this paper is to extract nucleus of white cells using image processing techniques.Here, nucleus of white cells are extracted from images using HSV color space and $\mathrm{YCbCr}$ color space. Using both of method, comparison between two methods has been checked. It has been proved that $\mathrm{YCbCr}$ is better than HSV color model by some experiment. Here, experiment is done on 15 images. HSV color model is given accurate result only on 5 images out of 15 and $\mathrm{YCbCr}$ color is given accurate model only on 13 images out of 15 . So accuracy of HSV and $\mathrm{YCbCr}$ model is $33.34 \%$ and $86.67 \%$ respectively. Here, white cell nucleus detection is useful to detect, blood cancer or Leukemia. It reduce processing time of pathologist and give result in short period of time.
\end{abstract}

\section{Keywords}

Nucleus of white cell detection, HSV color model, $\mathrm{YCbCr}$ color model, image processing

\section{INTRODUCTION}

There are lots of problem is accrued when our white cells are increasing more than normal rate. So chances of leukemia is increased. There are two type of leukemia (1) acute and (2) chronic. Another classification is done based on which type of immature cells are increased in our body. Due to immature blast of lymphoblast, lymphocytic leukemia and due to blast of myeloblast; myelogenous leukemia is occurred.

Here, our goal is to detect white cells from an images. To detect white cells from an image various image processing techniques are useful. Here, HSV color model and $\mathrm{YCbCr}$ color model will be used to detect different type of white cells. Here, due to proerythroblast, red cells are generated and due to metamyeloblast, platelets are generated.

Here, our goal is to detect white cells that generated due to mono blast, lymphoblast and myeloblast as shown in figure (1) [14] Classification of different cells can be shown in figure (2)[15]..

\section{BACKGROUND}

N. Anjana et al. suggest color enhancement of image using histogram equalization. Here contrast of a poor quality image is increased with to show clear image. Then, edge detection operation is performed and using histogram equalization method quality of image should be improved [1].

S. Arumugadevi et al. suggest color image segmentation method to detect particular information from an image. Here fuzzy C means and SOM (Self Organizing Map) are used for segmentation of image and proved it that these both methods give accurate result than $\mathrm{K}$ means Clustering techniques [2].

P. Ganesan et.al suggest the method for segmentation of satellite images. They suggest $\mathrm{YCbCr}$ color space and Fuzzy $\mathrm{C}$ means algorithm to segment satellite image. Fuzzy $\mathrm{C}$ means is very simple and easy method for segmentation of an image [3].

Emad A.Mohammed et.al. Suggest method to detect white cell of chronic lymphocytic leukemia. First image is converted RGB2 gray and then using Otsu's thresholding method it is converted into binary form. Edge detection algorithm is applied to detect edges of cells and then hole filling operation is performed. After that watershed algorithm is applied for segmentation of white cells [4]. Dipti Patra et.al suggest fuzzy based image segmentation method. To apply this method first image is captured using microscopic camera and then then to remove noise filtering techniques are used. After that, image is converted in to LAB color space and then some shape based features are applied for segmentation of cells [5].

Saiyed Umer et.al suggest the method to detect round object. For this, they performed circular Hough transform [6]. Siti Madihah Mazalan et.al suggest the method to count red cells. To count the different cells, circular Hough transform is used. In this method, limit of radius have to be defined and according to the value of limit different cells can be detected. 


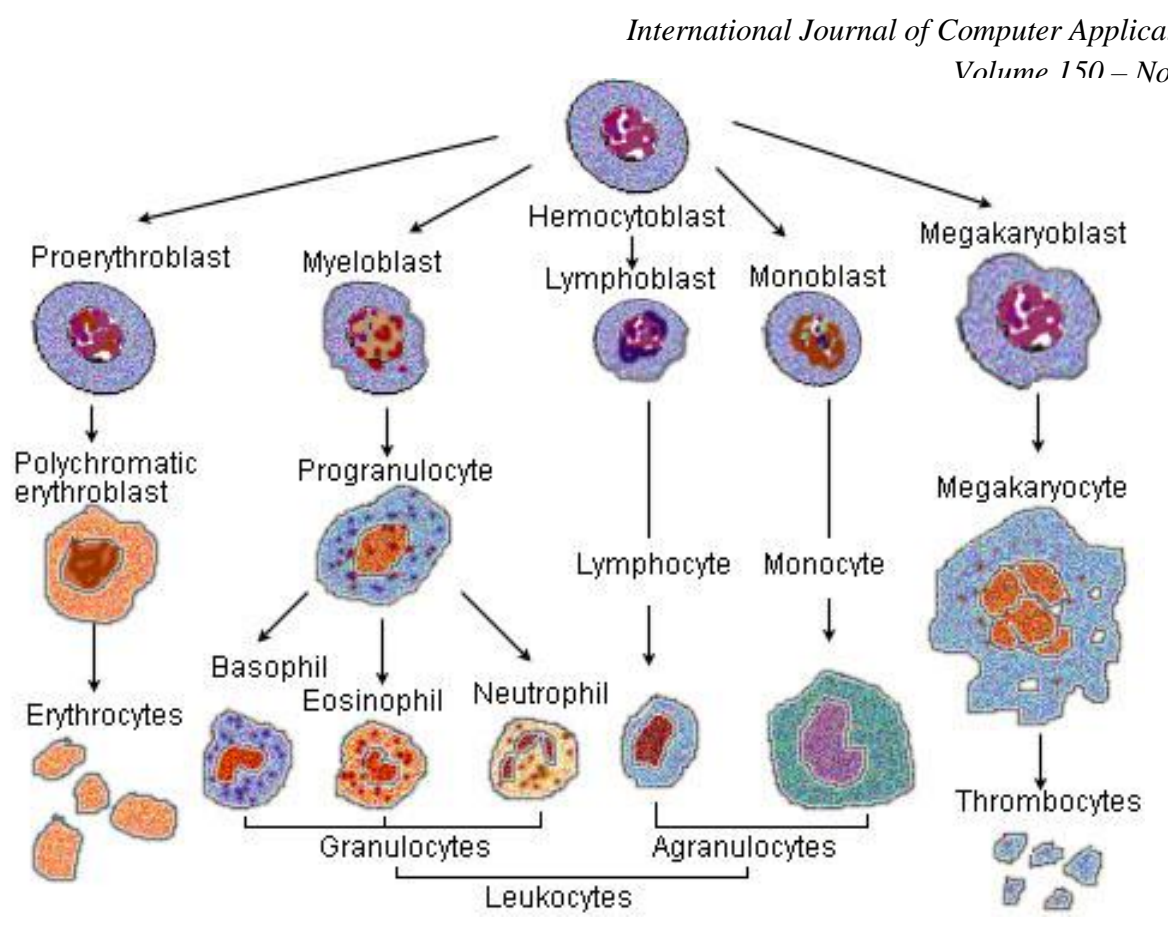

Figure (1). Cell generation cycle

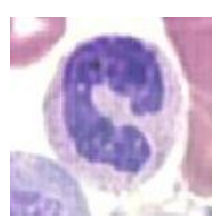

Band

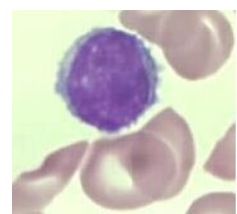

Lymphocyte

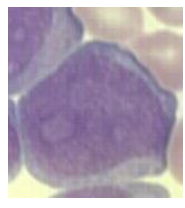

Myeloblast

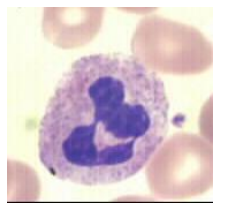

Neutrophil

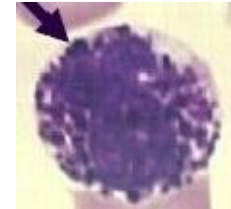

Basophil

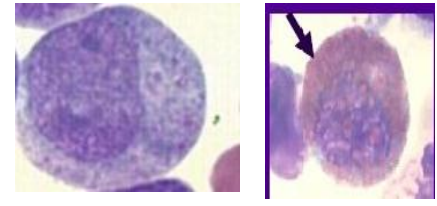

Promyelocyte Eosinophil

Figure 2 Different Types Of White Cells

To apply this method first image is converted in to gray and then using thresholding image is converted in to black and white then CHT algorithm is performed [7.

Ms. S. S. Adagale et.al suggest PCNN tempelate matching for counting white cells. First, image is converted from RGB to Gray level and then segmentation is done using PCNN algorithm and then remove unwanted object from an image using different morphological operation. After performing this operation again segmentation is done using template matching algorithm and then cells are counting. Overlapped cells are also detected using this method [8].

Lim Huey Nee et.al suggest the method to segment white cells from bone marrow images. RGB image is first converted into HSV color model and then S component is extracted from an image and some morphological operations like erosion or dilation is performed. After that image is converted into binary form and then watershed transform is applied on it [9].

Pradipta Maji et.al suggest mathematical morphology to characterize and count red cell. First, image is converted in to gray level and then Otsu's thresholding method is applied. After converting an image into binary form hole filling and smoothing operation is performed. After that category of cells are defined and overlapping cells can be detected [10].

Ling Li et.al suggest the method to detect precursor cell from bone marrow images. First image is converted in to binary form and then complement the image. After that area opening, hole filling and some morphological operations are performed [11].
Mausumi Maitra et.al suggest method for detection and counting white cells. Here, as a preprocessing technique edge detection, filtering and adaptive histogram equalization techniques are used. After that, Hough transform is used to count number of red cells [12].

Devkumar Das et.al suggest the method to recognize erythrocytes.

R,G,and B components are extracted from RGB image and using $\mathrm{G}$ component further process is performed. Now after extracting $G$ component, median filter is used and then watershed algorithm is applied for segmentation of an image. After that, shape and moment based features are applied to detect and to count red cells [13].

\section{METHODOLOGY}

\subsection{RGBtoHSV}

To separate only white cell, $\mathrm{HSV}$ and $\mathrm{YCbCr}$ method is describe here and compare both of the result and check accuracy. $\mathrm{H}$ is luminance component and $\mathrm{S}$ and $\mathrm{V}$ are chrominance component of an image. Original image 4(a) is taken from web sources [16].

Formula for conversion RGB to HSV color model:

$\mathrm{H}=\left\{\begin{array}{c}\theta \text { if } B \leq G \\ 360-\theta \text { if } B>G\end{array}\right.$ 
$\theta=\cos ^{-1}\left\{\frac{\frac{1}{2}[(R-G)+(R-B)]}{\left[(R-G)^{2}+(R-B)(G-B)\right]^{1 / 2}}\right\}$

$\mathrm{S}=1-\frac{3}{R+G+B} \min (R, G, B)$

$\mathrm{V}=\frac{(R+G+B)}{3}$
Here formula is given to extract component from HSV image. Result of this methods are shown in figure 4.

Algorithm to detect nucleus of white cell using HSV color model is shown in figure 3

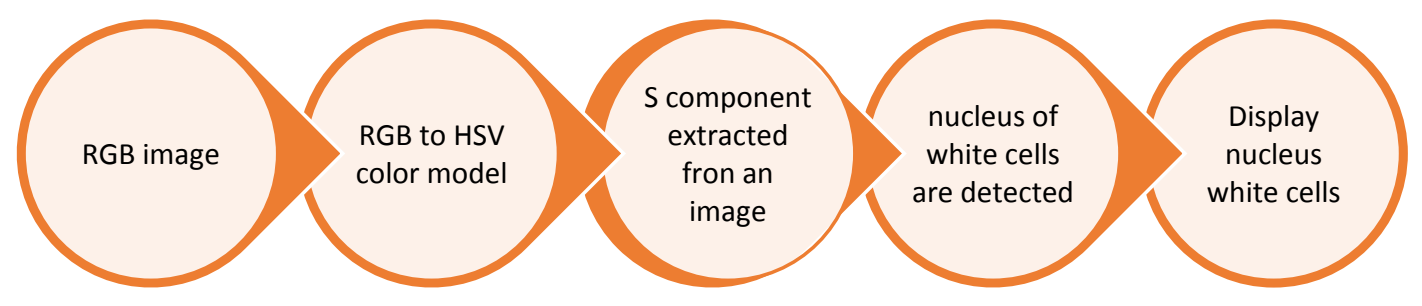

Figure3 Algorithm to detect nucleus of white cells

\subsubsection{Experimental Results}

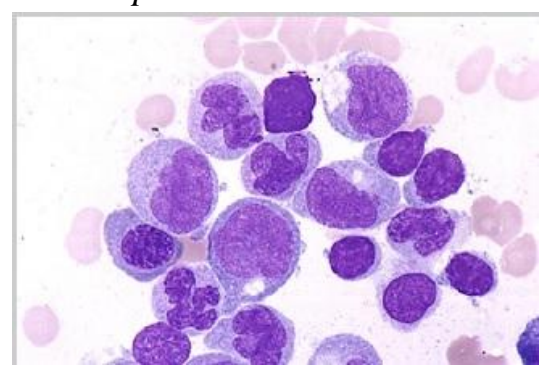

Figure 4(a) original image

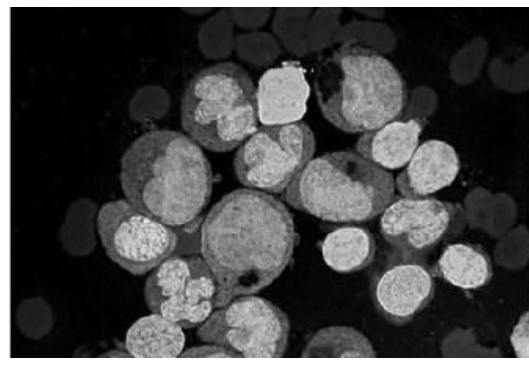

Figure 4(b) S component extracted

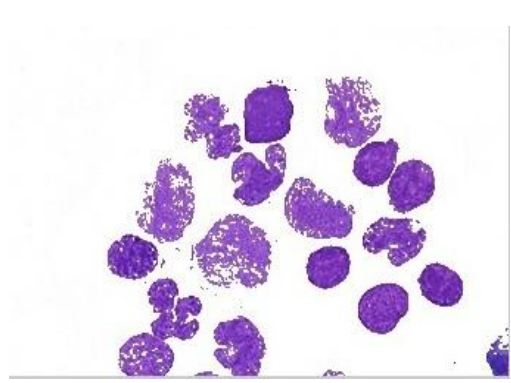

Figure 4(c) nucleus of white cells extracted

Figure (4) Process of RGB to HSV color model

Limitation of this method is, it is not applicable on every images.

\subsection{RGB to $\mathrm{YCbCr}$}

To detect white cells another method is to use YCbCr. In which first image is converted in to $\mathrm{YCbCr}$ model and then $\mathrm{Cb}$ component is extracted from image. Here $\mathrm{Y}$ is luminance component and $\mathrm{Cb}$ and $\mathrm{Cr}$ are chrominance component of an image.

Original image 6(a) is taken from web sources [17].

$\mathrm{Y}=0.299 \mathrm{R}+0.587 \mathrm{G}+0.114 \mathrm{~B}$
$\mathrm{Cb}=-0.1687 \mathrm{R}-0.3313 \mathrm{G}+0.5 \mathrm{~B}+128$

$\mathrm{Cr}=0.5 \mathrm{R}-0.4187 \mathrm{G}-0.0813 \mathrm{~B}+128$

Using chrominance component $\mathrm{Cb}$, nucleus of white cells are detected.

Algorithm to detect nucleus of white cell using $\mathrm{YCbCr}$ color model is shown in figure 5 . 


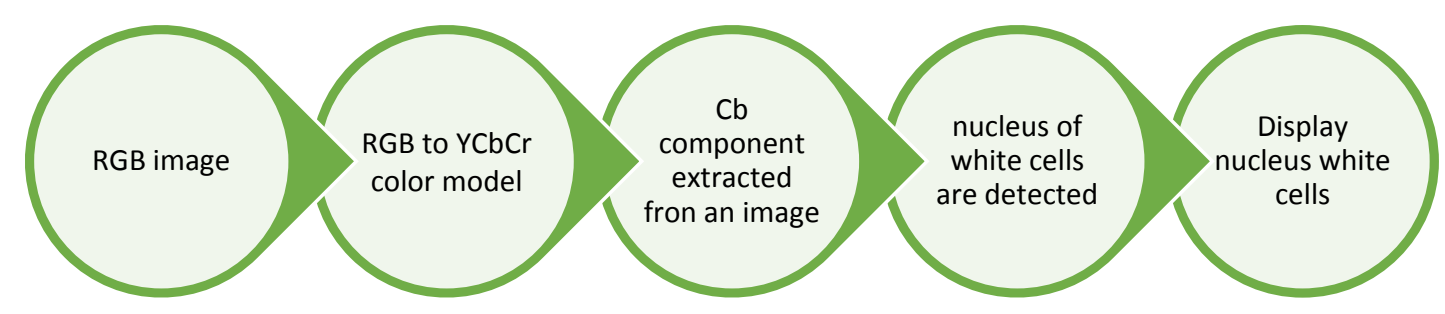

Figure 5. Algorithm to detect nucleus of white cells using $\mathrm{YCbCr}$

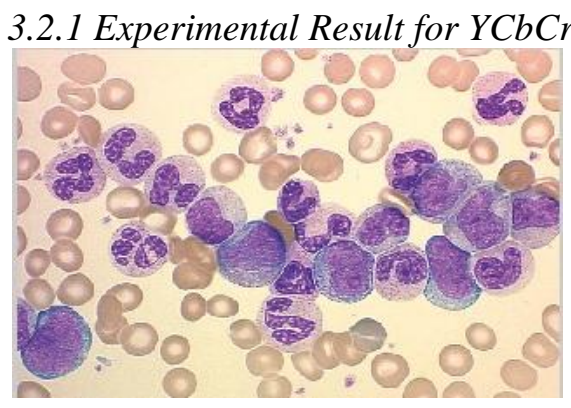

Figure 6(a) original image

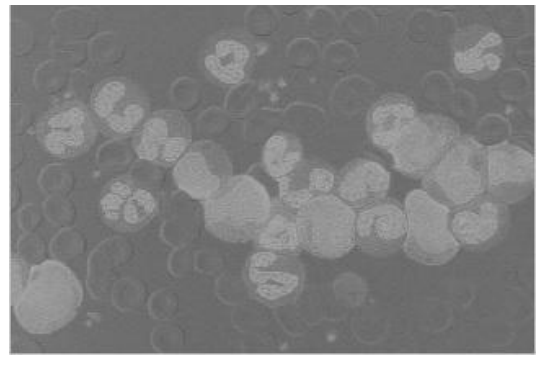

Figure 6(b) Cb component extracted

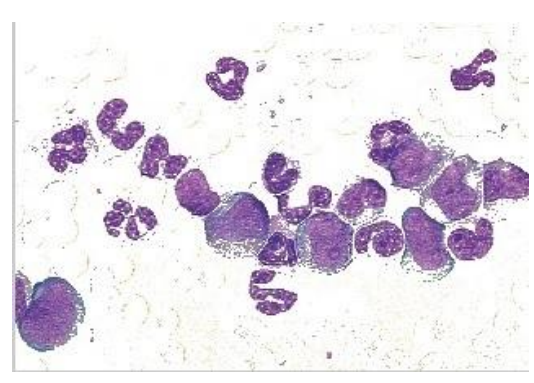

Figure 6(c) nucleus of white cells extracted

Figure (6) Process of RGB to YCbCr color model

\section{RESULT/DISSCUSION}

\begin{tabular}{|l|c|}
\hline Range of S component & $0.10<\mathrm{s}<0.50$ \\
\hline Range of Cb component & $105<\mathrm{Cr}<135$ \\
\hline \multicolumn{2}{|c|}{ Table 1. range of extracted component } \\
\hline
\end{tabular}

\begin{tabular}{|c|c|c|}
\hline $\begin{array}{c}\text { Number of images taken for } \\
\text { experiment }\end{array}$ & $\begin{array}{c}\text { Nucleus Correctly recognize in number of } \\
\text { images using HSV color model }\end{array}$ & $\begin{array}{c}\text { Nucleus correctly recognize in } \\
\text { number of images using YCbCr color } \\
\text { model }\end{array}$ \\
\hline 15 & 5 & 13 \\
\hline
\end{tabular}

\section{CONCLUSION}

After comparison of result RGB2HSV and RGB2YCbCr, it is concluded that $\mathrm{YCbCr}$ is the best method to detect nucleus of white cells. Rgb2HSV is performed correctly on 5 images out of 15 image and $\mathrm{RGB} 2 \mathrm{YCbCr}$ is performed correctly on 13 images out of 15 . Hence, $\mathrm{RGB} 2 \mathrm{YCbCr}$ method is very accurate for detection of white cells. Using HSV color model, $33.33 \%$ accuracy and using $\mathrm{YCbCr}$ model, $86.67 \%$ accuracy can be obtained. Hence, it is proved that $\mathrm{YCbCr}$ is better than HSV color model.

\section{FUTURE SCOPE}

After defined the best to detect nucleus of white cell, type of cell can be recognized. i.e, Normal cell or immature cell. After detection of this cell, type of leukemia or blood cancer can be classified.

\section{ACKNOWLEDGEMENT}

We are thankful to Bhaskaracharya Institute of Space Application and Geo informatics and thankful to Project Manager Manoj Pandya and Project Director M.B.Potdar. I also thankful to CHARUSAT University and Professor Hardik Modi for their constant support.

\section{REFERENCES}

[1] Anjana N, Priestley JJ, Nandhini V, Elamaran V. Color Image Enhancement using Edge Based Histogram Equalization. Indian Journal of Science and Technology. 2015 Nov $18 ; 8(1)$.

[2] Arumugadevi S, Seenivasagam V. Comparison of clustering methods for segmenting color images. Indian Journal of Science and Technology. 2015 Apr $1 ; 8(7): 670-7$. 
[3] Ganesan P, Rajini V, Sathish BS, Kalist V, Basha SK. Satellite image segmentation based on $\mathrm{YCbCr}$ color space. Indian Journal of Science and Technology. 2015 Jan 16;8(1):35-41.

[4] Mohammed EA, Mohamed MM, Naugler C, Far BH. Chronic lymphocytic leukemia cell segmentation from microscopic blood images using watershed algorithm and optimal thresholding. InElectrical and Computer Engineering (CCECE), 2013 26th Annual IEEE Canadian Conference on 2013 May 5 (pp. 1-5). IEEE.

[5] Mohapatra S, Samanta SS, Patra D, Satpathi S. Fuzzy based blood image segmentation for automated leukemia detection. InDevices and Communications (ICDeCom), 2011 International Conference on 2011 Feb 24 (pp. 1-5). IEEE.

[6] Umer S, Dhara BC. A fast iris localization using inversion transform and restricted circular Hough transform. InAdvances in Pattern Recognition (ICAPR), 2015 Eighth International Conference on 2015 Jan 4 (pp. 1-6). IEEE.

[7] Mazalan SM, Mahmood NH, Razak MA. Automated red blood cells counting in peripheral blood smear image using circular Hough transform. InArtificial Intelligence, Modelling and Simulation (AIMS), 2013 1st International Conference on 2013 Dec 3 (pp. 320-324). IEEE.

[8] Adagale SS, Pawar SS. Image segmentation using PCNN and template matching for blood cell counting. InComputational Intelligence and Computing Research (ICCIC), 2013 IEEE International Conference on 2013 Dec 26 (pp. 1-5). IEEE.

[9] Lim HN, Mashor MY, Hassan R. White blood cell segmentation for acute leukemia bone marrow images. InBiomedical Engineering (ICoBE), 2012 International Conference on 2012 Feb 27 (pp. 357-361). IEEE.
[10] Maji P, Mandal A, Ganguly M, Saha S. An automated method for counting and characterizing red blood cells using mathematical morphology. InAdvances in Pattern Recognition (ICAPR), 2015 Eighth International Conference on 2015 Jan 4 (pp. 1-6). IEEE.

[11] Li L, Cao G, Shi J, Wu H, Zhang X. Detecting immature precursor cells in pathological images of bone marrow based on morphology. InFuzzy Systems and Knowledge Discovery (FSKD), 2010 Seventh International Conference on 2010 Aug 10 (Vol. 5, pp. 2190-2194). IEEE.

[12] Maitra M, Gupta RK, Mukherjee M. Detection and counting of red blood cells in blood cell images using Hough transform. International journal of computer applications. 2012 Jan 1;53(16).

[13] Das D, Ghosh M, Chakraborty C, Pal M, Maity AK. Invariant moment based feature analysis for abnormal erythrocyte recognition. InSystems in medicine and biology (ICSMB), 2010 international conference on 2010 Dec 16 (pp. 242-247). IEEE.

[14] Figure 1 the formation of myeloid and lymphoid series of cell [Online] Available at http://masonposner.com/afisheyeview/wpcontent/uploads/2010/03/380pxIllu_blood_cell_lineage.jpg

[15] Figure 2 Different type of white cells[Online] Available at: https: // www.medschool.lsuhsc.edu / pathology/ docs/ Blood\%20Cell\%20Morphology\%20Tutorial.pdf 4 April 2016

[16] Figure 4(a) [Online]: Available at: http://imagebank.hematology.org /getimagebyid /2150? Size $=34$ April 2016

[17] Figure 6(a) [Online]: Available at: http:// www.clevelandclinicmeded.com / medicalpubs / diseasemanagement / hematology-oncology/chronicleukemias/images/figure-1.jpg 4 April 2016 